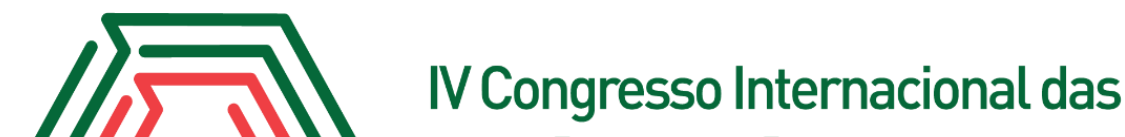 Licenciaturas COINTER - PDVL 2017
}

\section{O PROCESSO DE AVALIAÇÃO DO CONHECIMENTO CIENTÍFICO OPORTUNIZANDO EXPERIENCIAS NA FORMAÇÃO DOCENTE}

\author{
Apresentação: Relato de Experiência
}

Tatiane de Oliveira Lourenço ${ }^{1}$; Evanuel Justo Ferreira ${ }^{2}$; Jéssica Nicolle Rodrigues

$$
\text { Matias }^{3} \text {; Marcus Luiz dos Santos Menezes }{ }^{4}
$$

\section{Introdução}

A importância da formação docente tem sido discutida nos cursos de licenciatura, inclusive no que se refere à importância dos futuros docentes aprenderem e compreenderem com a vivência e as experiências oportunizadas durante o curso. Espera-se que essas experiências sirvam de contribuição para o desempenho de um papel significativo em suas carreiras docentes. Diante das dificuldades apresentadas nas escolas públicas, surge o Programa Institucional de Bolsa de Iniciação à Docência - PIBIB, com o propósito de inserir os bolsistas no âmbito da escola promovendo o ensino-aprendizagem. O presente trabalho irá abordar a atuação dos bolsistas do PIBID como avaliadores da II Mostra de Ciências no Educandário Nossa Senhora das Vitórias - ENSV localizada na cidade de Assú - RN.

\section{Relato de Experiência}

A escola abrange diferentes sujeitos com pensamentos e características distintas e a educação presente possui o papel de instruir esses discentes a atuarem em sociedade. $\mathrm{O}$ professor busca por atividades que instigue os alunos a pensar, a problematizar e contextualizar com o mundo a sua volta que desperte no aluno suas potencialidades por meio dos desafios e dificuldades propostas em sala de aula. A aplicabilidade dessas atividades é relacionada à teoria e a prática, sendo indissociável como práxis (PIMENTA, 2005, apud, MEDEIROS E CABRAL, 2006). Dentre essas atividades podemos destacar a feira de ciência como metodologia de ensino para diferenciar as aulas ministradas tendo como foco a exposição de trabalhos científicos desenvolvidos por alunos, que demonstram através de

\footnotetext{
${ }^{1}$ Licenciatura em Química, IFRN, tatiane.lou2@hotmail.com

${ }^{2}$ Licenciatura em Química, IFRN, evanuel.justo@hotmail.com

${ }^{3}$ Graduada em Química, Escola Estadual Manoel de Melo Montenegro,nicollemattias@gmail.com

${ }^{4}$ Especialista em Química, Instituto Federal de Educação, Ciência e Tecnologia Rio Grande do Norte, marcus.menezes@ifrn.edu.br
} 
apresentações orais a troca de informações e conhecimentos entre si e com o público a sua volta (ORMASTRONI, 1990, p. 7, apud, MACHADO, 2014, p. 3).

Os bolsistas do PIBID de Química do Instituto Federal de Educação, Ciência e Tecnologia Rio Grande do Norte - IFRN, campus Ipanguaçu/RN, foram selecionados pelo ENSV para atuarem como avaliadores através da professora supervisora do programa, uma vez que esta atua também na escola em questão, além da rede pública de ensino. Os alunos do Ensino Fundamental e Médio participaram da II Mostra de Ciências com apresentações que abordavam a temática Meio Ambiente, onde expuseram maquetes e protótipos produzidos por eles para a explanação. Os bolsistas avaliaram os alunos através da explicação, postura, clareza do tema e domínio do assunto.

Imagem 1: Avaliadores da II Mostra de Ciência. Fonte: ENSV
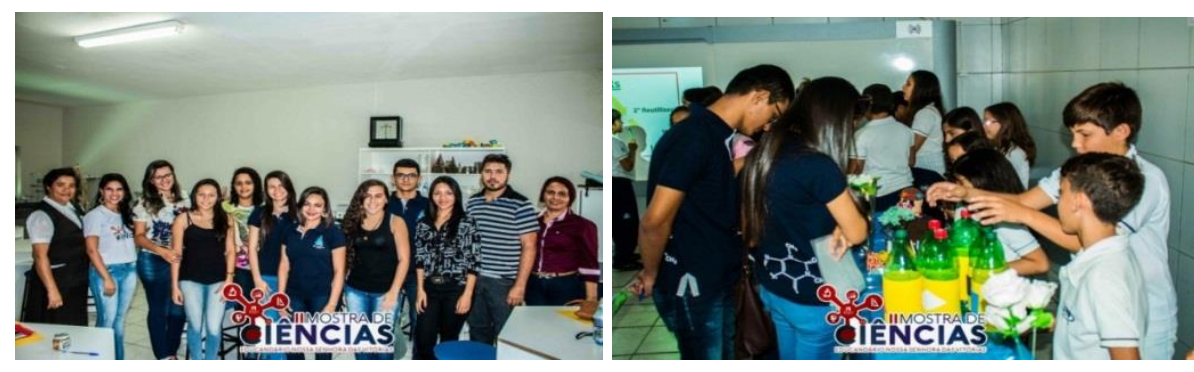

\section{Considerações}

O desenvolvimento deste trabalho permitiu aos bolsistas do PIBID uma aproximação com os alunos em seu espaço escolar, contribuindo na construção de sua formação docente. A proposta surge para envolver os bolsistas em atividades que os estimule relacionar a teoria e a prática permitindo uma progressão significativa enquanto profissional.

\section{Referências}

MACHADO, S.S.; BLANCO, A.J.V.; BARROS, V.F.A.; CARDOSO, E.B. A Feira de Ciências como ferramenta educacional para formação de futuros pesquisadores. Congresso Ibero-americano de Ciência, Tecnologia, Innovación y Educación. Buenos Aires, 2014.

MEDEIROS, M. V.; CABRAL, C. L. DE. O. FORMAÇÃO DOCENTE: DA TEORIA À PRÁTICA, EM UMA ABORDAGEM SÓCIO-HISTÓRICA. Pontifícia Universidade Católica de São Paulo Programa de Pós-Graduação Educação: Currículo. Revista ECurriculum. 2006. 